\title{
Microstructure and corrosion resistance of ultrasonic micro-arc oxidation biocoatings on magnesium alloy
}

\author{
Lijie $\mathrm{QU}^{a, b}$, Muqin $\mathrm{LI}^{a, b,{ }^{*}}$, Miao LIU ${ }^{c}$, Erlin ZHANG ${ }^{b}$, Chen $\mathrm{MA}^{b}$ \\ ${ }^{a}$ State Key Laboratory of Advanced Welding and Joining, Harbin Institute of Technology, Harbin 150001, China \\ ${ }^{b}$ Department of Materials Science and Engineering, Jiamusi University, Jiamusi 154007, China \\ ${ }^{c}$ Department of Stomatology, Jiamusi University, Jiamusi 154007, China
}

Received: February 01, 2013; Revised: April 12, 2013; Accepted: April 15, 2013

CThe Author(s) 2013. This article is published with open access at Springerlink.com

\begin{abstract}
The ultrasonic micro-arc oxidation (UMAO) was used to fabricate ceramic coatings on magnesium alloy. UMAO coatings were produced at $60 \mathrm{~W}$ input ultrasonic. The effects of the ultrasound on the microstructure, phase composition, elemental distribution and corrosion resistance of the coatings were extensively investigated by scanning electron microscopy (SEM), X-ray diffraction (XRD), energy-dispersive X-ray spectrometry (EDX) and electrochemical workstation. The results showed that ultrasound improved the homogeneous distribution of micro-porous structure. The coatings were mainly composed of $\mathrm{MgO}$ ceramic and small amount of calcium and phosphorus with porous structure. The $\mathrm{Ca} / \mathrm{P}$ ratio of the coatings increased when $60 \mathrm{~W}$ ultrasonic was used. The corrosion potential in simulated body fluid (SBF) changed from $-1.583 \mathrm{~V}$ of bare magnesium alloy to $-0.353 \mathrm{~V}$ of magnesium alloy coated under $60 \mathrm{~W}$ ultrasonic. The corrosion resistance of UMAO coatings was better than that of MAO coatings.
\end{abstract}

Keywords: micro-arc oxidation (MAO); ultrasonic treatment; magnesium alloy; microstructure; corrosion resistance

\section{Introduction}

Magnesium and its alloys have been investigated as implants for almost two centuries due to the advantages and obvious benefits from biodegradable metal implants [1,2]; however, commercial implants containing magnesium and its alloys are still not available until now. Magnesium is present in high concentration in sea water and is the eighth most abundant element on earth. Furthermore, it is the fourth most abundant cation in human body. It also has excellent specific strength and low density, inherent

\footnotetext{
* Corresponding author.

E-mail: jmsdxlimuqin@163.com
}

biocompatibility, and adequate mechanical properties $[3,4]$. Unfortunately, magnesium is too reactive and generally exhibits a poor corrosion resistance because of high dissolution tendency in biological environments. Protective coating is an effective way to improve the corrosion resistance of magnesium and its alloys [5]. Many technologies have been used to obtain protective coatings, such as electroplating, thermal spraying, chemical conversion coatings, bio-mimetic approach, electrochemical deposition and anodization, and so on [6-9]. Recently, micro-arc oxidation (MAO) treatment, a common technique for the corrosion protection of magnesium alloys in industrial sector, has been used for the surface modification of magnesium and its alloys for biomedical applications due to their 
low cost and simplicity in operation.

The porous microstructure of MAO ceramic coatings would also result in an increase in corrosion rate of magnesium alloys. So many efforts have been done to improve the corrosion resistance of magnesium alloys during the MAO process. Zheng et al. [10] changed the applied voltage to increase the corrosion resistance of $\mathrm{Mg}-\mathrm{Ca}$ alloy. Liang et al. [11] chose silicate and phosphate electrolytes to improve the corrosion resistance of magnesium alloy. Additives were used to improve corrosion resistance of the coatings [12-14]. The corrosion resistance was improved greatly; however, MAO coatings still exhibited poor corrosion resistance [15]. The porous microstructure might offer a beneficial surrounding for cells [16-19], but $\mathrm{MgO}$ exhibited poor biological activity. Calcium and phosphorus coatings on magnesium alloy were potential biomaterials [20,21]. So MAO combined with other methods was used to improve the corrosion resistance of magnesium alloys and the biocompatibility of MAO coatings. Hu et al. [22] used MAO with chemical deposition to prepare calcium phosphate coating on the surface of micro-arc oxidized magnesium alloy. Electro-deposition was also used to fabricate a top layer of DCPD on AZ80 Mg alloy coated by MAO to improve the corrosion resistance and bioactivity [23]. These composite methods need two steps, though the corrosion resistance of magnesium alloy and the bioactivity of $\mathrm{MgO}$ layer were improved evidently.

Recently, ultrasound technology in the synthesis of new materials has played a very significant effect [24]. Mechanical, thermal and active effects generated by ultrasonic and liquid medium make ultrasonic wave applied in surface engineering and electrochemistry [25]. At the same time, ultrasound is beneficial to inducing chemical modification on many materials $[26,27]$. Ultrasound would have cavitation effect when the ultrasonic power density is equal to or greater than $0.3 \mathrm{~W} / \mathrm{cm}^{2}$. In the present study, the minimum ultrasonic power density was applied during the MAO process to fabricate ultrasonic micro-arc oxidation (UMAO) coatings on magnesium alloy to develop a one-step method to improve corrosion resistance of magnesium alloy and make the excellent biological performance of UMAO coatings. Furthermore, the microstructure and corrosion resistance properties of UMAO coatings were studied.

\section{Experiment}

\subsection{Sample preparation}

Magnesium bar with a diameter of $15 \mathrm{~mm}$ was sliced into thin samples with $2 \mathrm{~mm}$ in thickness and $15 \mathrm{~mm}$ in diameter. The samples were ground with $\mathrm{SiC}$ papers progressively up to 1500 grits followed by ultrasonic cleaning in acetone and ethanol for $5 \mathrm{~min}$, respectively. The composition and mechanical properties of the magnesium alloy are shown in Table 1. UMAO treatment was carried out at $300 \mathrm{~V}$ pulse voltage with a duty cycle of $10 \%$ and a frequency of $700 \mathrm{~Hz}$. The electrolyte, comprising $20 \mathrm{~g} / \mathrm{L} \mathrm{Ca}\left(\mathrm{H}_{2} \mathrm{PO}_{4}\right)_{2} \cdot \mathrm{H}_{2} \mathrm{O}$ and $13 \mathrm{~g} / \mathrm{L} \mathrm{NaOH}$, was prepared using distilled water and used continuously during the treatment with $60 \mathrm{~W}$ (the ultrasonic power density was $\left.0.3 \mathrm{~W} / \mathrm{cm}^{2}\right), 40 \mathrm{kHz}$ ultrasound. A sheet of $316 \mathrm{~L}$ stainless steel with dimensions of $30 \mathrm{~mm} \times 10 \mathrm{~mm}$ was used as the cathode. Samples treated in the electrolyte with and without ultrasound process for $5 \mathrm{~min}$ were rinsed in distilled water and dried in air, respectively.

\section{2 Characterization}

The specimens were examined by scanning electron microscope (SEM, JSM-6360LV) equipped with energy dispersive X-ray (EDX) analysis facility. The phase composition of the coatings was investigated by $\mathrm{X}$-ray diffraction (XRD, Rigaku D/max-rB) using $\mathrm{Cu}$ $\mathrm{K} \alpha$ radiation, with a step size of $1^{\circ}$ and a scan range from $10^{\circ}$ to $90^{\circ}$ (in $2 \theta$ ). Polarization curves tested in simulated body fluid (SBF) were conducted using CHI660C potentiostat with a scan rate of $0.01 \mathrm{mV} / \mathrm{s}$, from $-2.5 \mathrm{~V}$ to $1 \mathrm{~V}$. SBF was composed of $7.996 \mathrm{~g} / \mathrm{L}$ $\mathrm{NaCl}, 0.35 \mathrm{~g} / \mathrm{L} \quad \mathrm{NaHCO}_{3}, 0.224 \mathrm{~g} / \mathrm{L} \mathrm{KCl}, 0.228 \mathrm{~g} / \mathrm{L}$ $\mathrm{K}_{2} \mathrm{HPO}_{4} \cdot 3 \mathrm{H}_{2} \mathrm{O}, \quad 0.305 \mathrm{~g} / \mathrm{L} \quad \mathrm{MgCl}_{2} \cdot 6 \mathrm{H}_{2} \mathrm{O}, \quad 0.278 \mathrm{~g} / \mathrm{L}$ $\mathrm{CaCl}_{2}$, and $0.071 \mathrm{~g} / \mathrm{L} \mathrm{Na}_{2} \mathrm{SO}_{4}$.

Table 1 Composition and mechanical properties of the magnesium alloy

\begin{tabular}{|c|c|c|c|c|c|c|c|}
\hline \multicolumn{5}{|c|}{ Composition (wt\%) } & \multicolumn{3}{|c|}{ Mechanical property } \\
\hline $\mathrm{Zn}$ & $\mathrm{Zr}$ & $\mathrm{Mn}$ & $\mathrm{Ca}$ & $\mathrm{Mg}$ & Tensile strength (MPa) & Yield strength (MPa) & Percentage elongation (\%) \\
\hline 5.9 & 0.59 & 0.08 & 0.2 & Bar & 244.8 & 105.7 & 10.6 \\
\hline
\end{tabular}




\section{Results and discussion}

\section{1 Morphologies and elemental distribution of the coatings}

The surface and cross morphologies of coatings on magnesium alloy are shown in Fig. 1. The MAO coating without the ultrasonic treatment is shown in Figs. 1(a) and 1(c). Nonhomogeneous distribution of the micro-porous structure and uneven surface are seen and there is local cracking on the surface of coating in Fig. 1(a). The cross morphology shows inter-connective porous structure, and there is no obvious dense layer in Fig. 1(c). In theory, all of these structures do not offer good protective effect on the magnesium alloy substrate. The MAO coating with the ultrasonic treatment is shown in Figs. 1(b) and 1(d). Homogeneous distribution of micro-porous structure and even surface are seen in Fig. 1(b). What is more, local cracking on the surface of UMAO coatings disappears and the hole sizes increase compared with that of MAO coatings. The thickness of dense layer increases and independent hole is formed in Fig. 1(d).

The atomic force microscopy (AFM) analyses, performed with scanning area of $25 \mu \mathrm{m}^{2}$, show the cross topographies of MAO and UMAO coatings in Fig. 2. They are all composed of nano-particles, but the three-dimensional morphologies are different. There is island structure in MAO coating and column layer structure in UMAO coating, which indicates that the ultrasonic changes the growth pattern of coatings. The system of micro-arc oxidation and magnesium matrix with ultrasound obtains the energy $\Delta U$ from ultrasonic vibration. The energy provides the condition for the activation of magnesium matrix. So the initial reaction in MAO process happens as follows [24]:

$$
\begin{gathered}
\mathrm{H}_{2} \mathrm{O} \stackrel{\Delta U}{\longrightarrow} \mathrm{H}^{+}+\mathrm{OH}^{-} \\
2 \mathrm{H}^{+} / \mathrm{H}^{+} \longrightarrow \mathrm{H}_{2} / \mathrm{H}_{2} \mathrm{O}_{2} / \mathrm{H}_{2} \mathrm{O} \\
2 \mathrm{OH}^{-} \longrightarrow \mathrm{H}_{2} \mathrm{O}+\mathrm{O}^{2-} \\
\mathrm{H}_{2} \mathrm{O}+\mathrm{Mg} \longrightarrow \mathrm{MgO}+\mathrm{H}_{2} \mathrm{O} \\
\mathrm{Mg} \stackrel{\Delta G^{*}}{\longrightarrow} \mathrm{Mg}^{2+}+2 \mathrm{e} \\
\mathrm{Mg}^{2+}+\mathrm{O}^{2-} \longrightarrow \mathrm{MgO}
\end{gathered}
$$

Magnesium matrix rapidly achieves the activation status when MAO system absorbs energy $\Delta G^{*}$ obtained from ultrasound, which makes electron transfer from magnesium matrix and form $\mathrm{Mg}^{2+}$ [28]. $\mathrm{Mg}^{2+}$ quickly passes through the solid phase $\mathrm{MgO}$ and arrives at the interface of magnesium and electrolyte. However, $\mathrm{MgO}$ is an insulation layer which hinders electron transfer. The effect of ultrasonic cavitation makes the movable carrier $\mathrm{O}^{2-}$ move to the interface and react with $\mathrm{Mg}^{2+}$ to form the dense layer [29]. Therefore, the thickness of dense layer of UMAO coating is greater

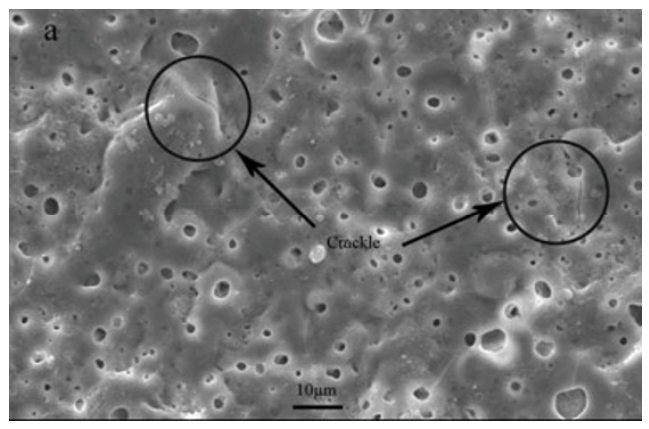

(a) $0 \mathrm{~W}$

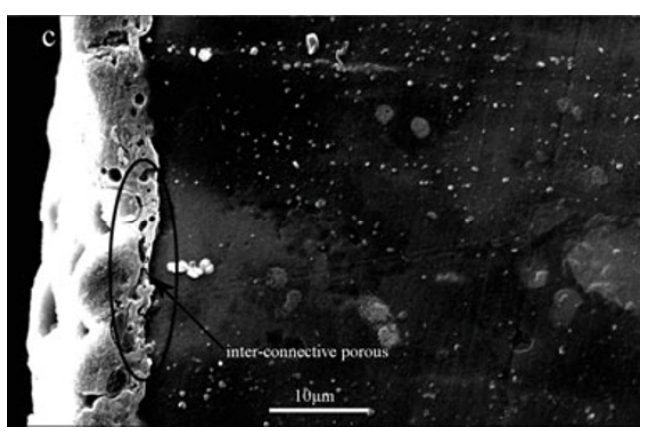

(c) $0 \mathrm{~W}$

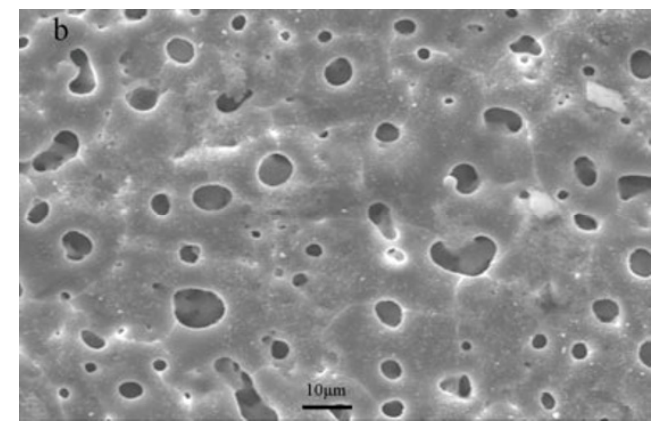

(b) $60 \mathrm{~W}$

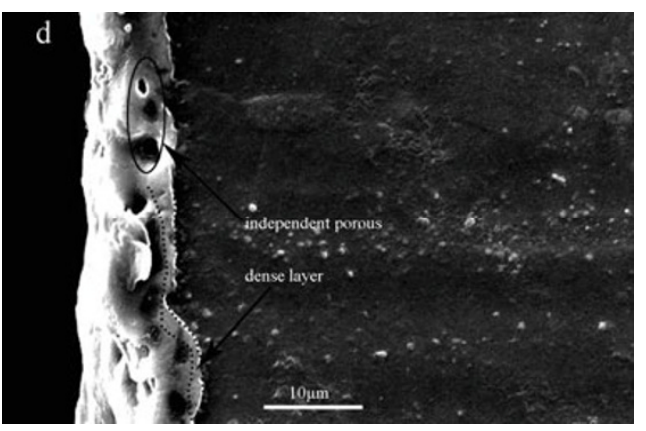

(d) $60 \mathrm{~W}$

Fig. 1 Surface and cross morphologies of MAO and UMAO coatings. 


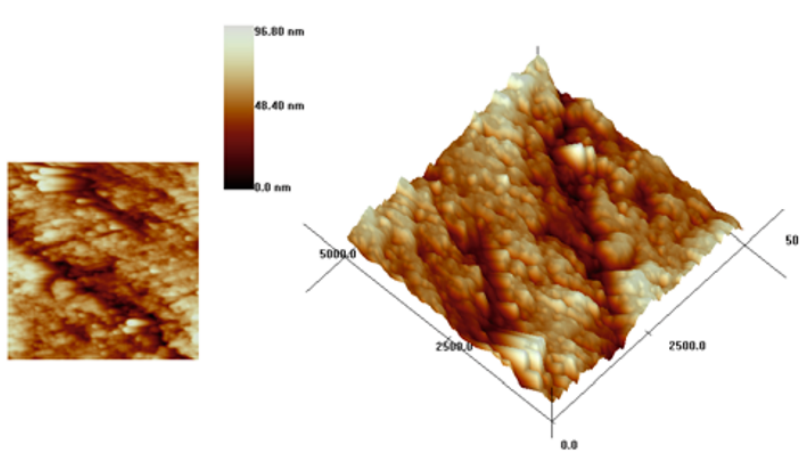

(a) $0 \mathrm{~W}$

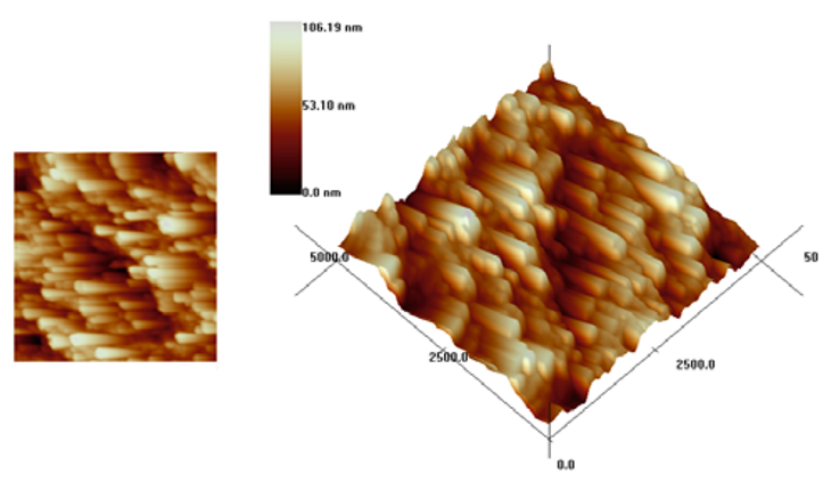

(b) $60 \mathrm{~W}$

Fig. 2 AFM topographies of the cross coatings coated under different ultrasonic powers.

than that of MAO coating. At the same time, mechanical and cavitation effects of ultrasound cause damage to outward growth layer. The results of cross dimension show that the total thickness of UMAO coated under $60 \mathrm{~W}$ ultrasonic power is accordant with that of MAO coating (shown in Figs. 1(c) and 1(d)). $\mathrm{MgO}$ film is a necessary condition for micro-arc oxidation, so ultrasound accelerates the process of MAO to make the crystal energy increase. The higher crystal energy promotes crystal orientation growth, which shows different crystal morphology and size. The maximum crystal sizes of UMAO and MAO coatings are $106.19 \mathrm{~nm}$ and $96.80 \mathrm{~nm}$, respectively.

The ratio of calcium and phosphorus $(\mathrm{Ca} / \mathrm{P})$ is calculated according to Fig. 3. $\mathrm{Mg}$ and $\mathrm{O}$ elements are detected and the electrolyte elements are also the constituents of the coatings. It can be found that the relative $\mathrm{Ca} / \mathrm{P}$ ratio increases from 0.252 to 0.380 when

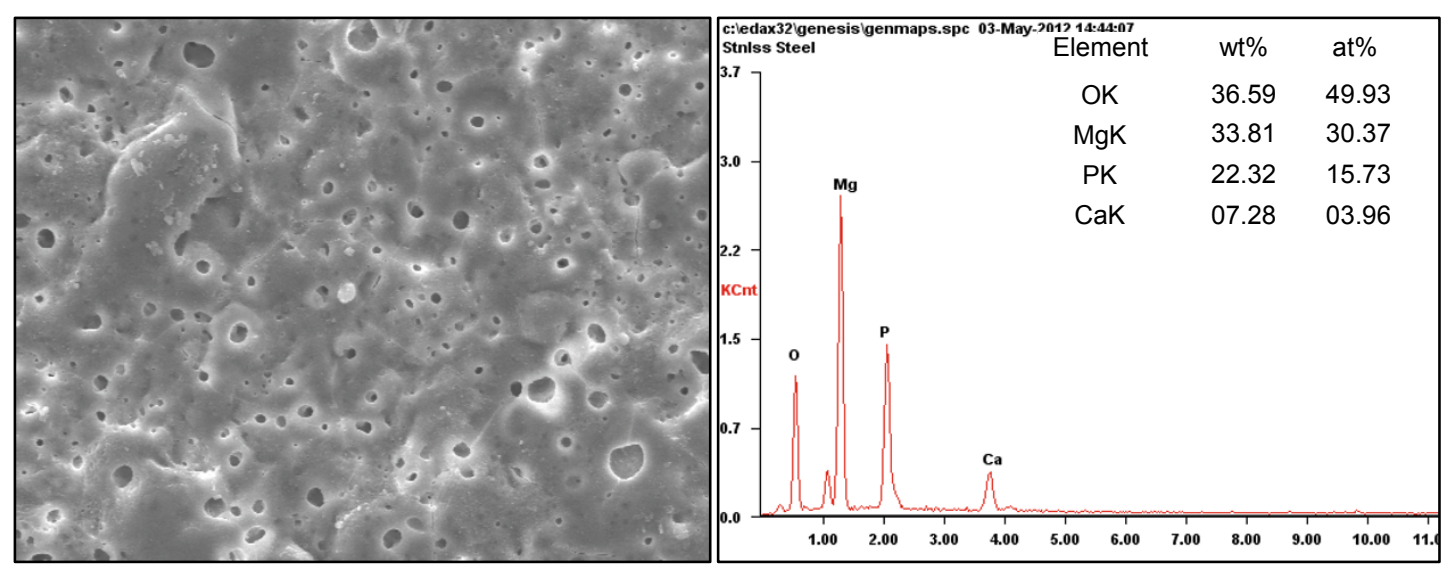

(a) $0 \mathrm{~W}$

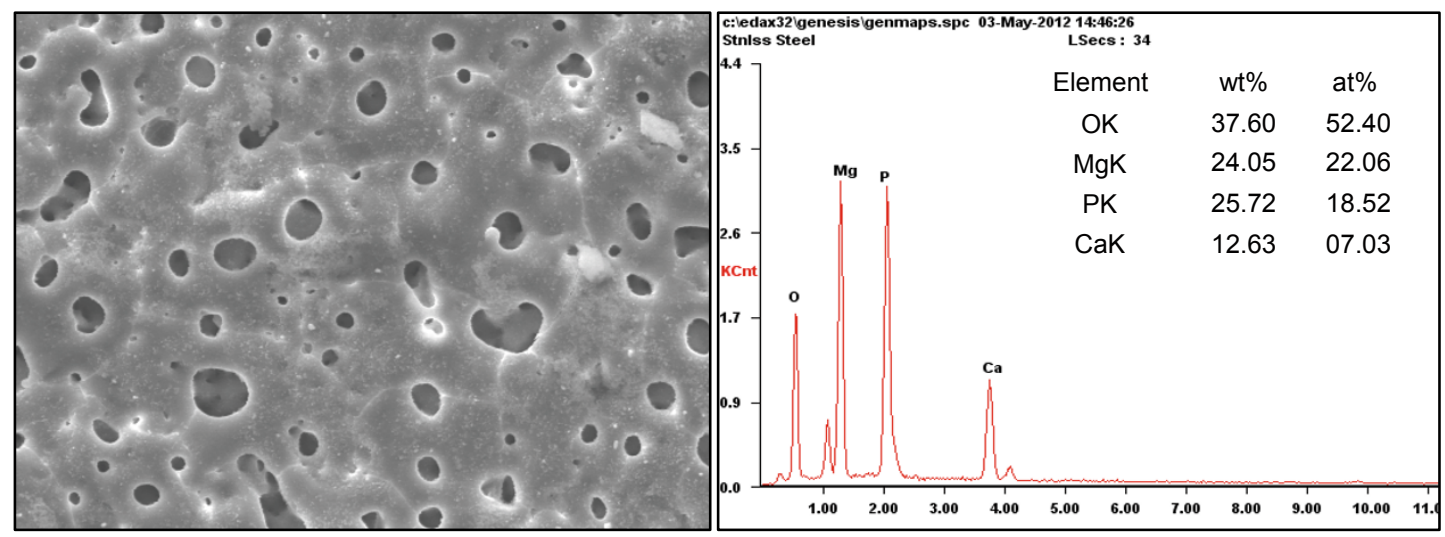

(b) $60 \mathrm{~W}$

Fig. 3 EDX analysis of coatings coated under different ultrasonic powers. 
the ultrasonic power is input. At the same time, the contents of calcium and phosphorus also increase. When ultrasound passes through an electrolyte, it produces rapidly fluctuating pressures to make rapid movement of the fluid and phosphate ions will be introduced into the coatings [30]. A thin oxidation film forms on the base metal at the beginning of oxidation process. Meanwhile, $\mathrm{Ca}_{3}\left(\mathrm{PO}_{4}\right)_{2}$ sol particles and $\mathrm{PO}_{4}^{3-}$ anions in the electrolyte are incorporated into oxidation film. Ultrasound in the MAO process increases the electrolyte temperature which makes $\mathrm{Ca}_{3}\left(\mathrm{PO}_{4}\right)_{2}$ sol particles generate violent collision with each other to form relative big sol particles [31]. The released energy of ultrasound by mechanical and cavitation effects lowers the critical voltage value of MAO, which makes the response of MAO be facilitated. In contrast, the forming high energy of ultrasound warms the anode and more electrical sparks take place on the vicinity of the anode. Under such a high energetic field, big sol particles $\mathrm{Ca}_{3}\left(\mathrm{PO}_{4}\right)_{2}$ and $\mathrm{PO}_{4}{ }^{3-}$ ions in the electrolyte move toward the anode faster and enter into the coatings, which makes the quantity of $\mathrm{Ca}_{3}\left(\mathrm{PO}_{4}\right)_{2}$ increase in the coatings. The calcium and phosphorus film is deposited on the magnesium substrate and the $\mathrm{Ca} / \mathrm{P}$ ratio of UMAO coating increases compared with that of MAO coating, which indicates that the reaction is activated more easily by the ultrasound agitation.

\section{2 Composition of coatings}

The phase composition of MAO coatings formed with and without ultrasonic power is examined, as shown in Fig. 4. This reveals that the coatings are mainly $\mathrm{MgO}$. UMAO mainly includes two stages, namely the

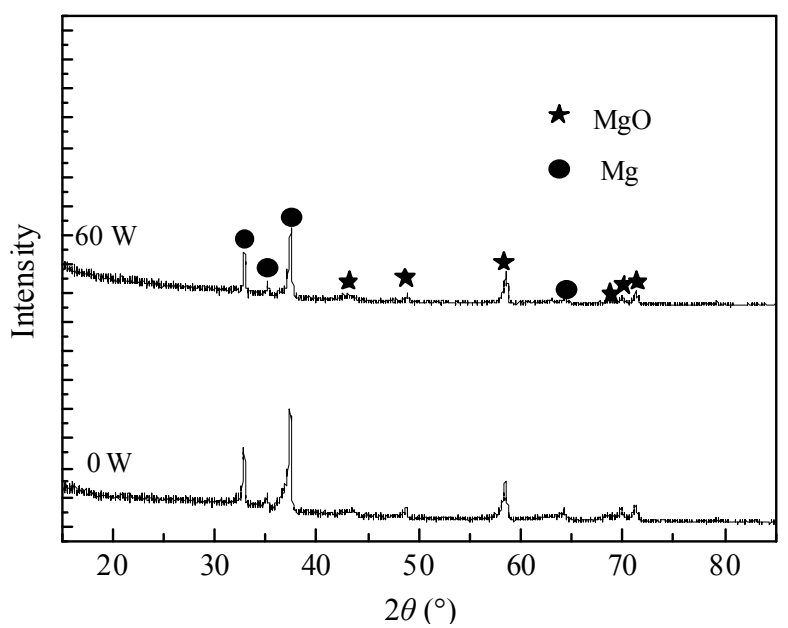

Fig. 4 XRD patterns of magnesium alloy coated under different ultrasonic powers. ultrasound exciting stage and interaction of ultrasound and micro-arc oxidation. At the first stage, ultrasound plays the main role in the forming process of movable carrier $\mathrm{O}^{2-}$, which accelerates the MAO reaction process. The phase of coatings is not changed though ultrasound promotes the coating in growth. At the same time, increased voltage in the second stage also makes the following reaction happen [32]:

$$
\begin{aligned}
& \mathrm{H}_{2} \mathrm{O} \longrightarrow \mathrm{H}^{+}+\mathrm{OH}^{-} \\
& 2 \mathrm{OH}^{-} \longrightarrow \mathrm{H}_{2} \mathrm{O}+\mathrm{O}^{2-} \\
& \mathrm{Mg}^{2+}+\mathrm{O}^{2-} \longrightarrow \mathrm{MgO}
\end{aligned}
$$

No peak corresponding to calcium and phosphorus phases are detected by XRD. However, EDX analysis results indicate that there exist calcium and phosphorus elements in the coatings, as seen in Fig. 5. The reasons for the phenomenon can be the following two aspects: calcium and phosphorus exist in an amorphous phase due to the fast cooling rate of the meltdown thing, and the amount of calcium and phosphorus is too low to be

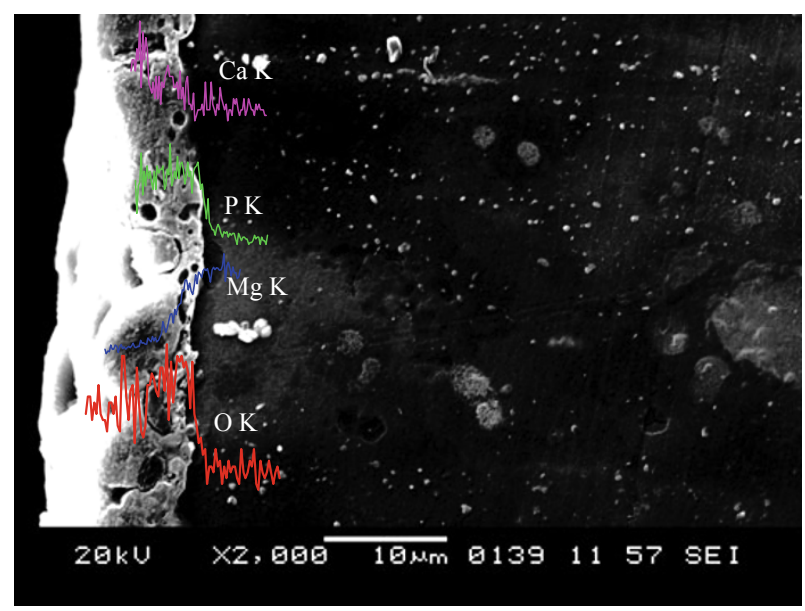

(a) $0 \mathrm{~W}$

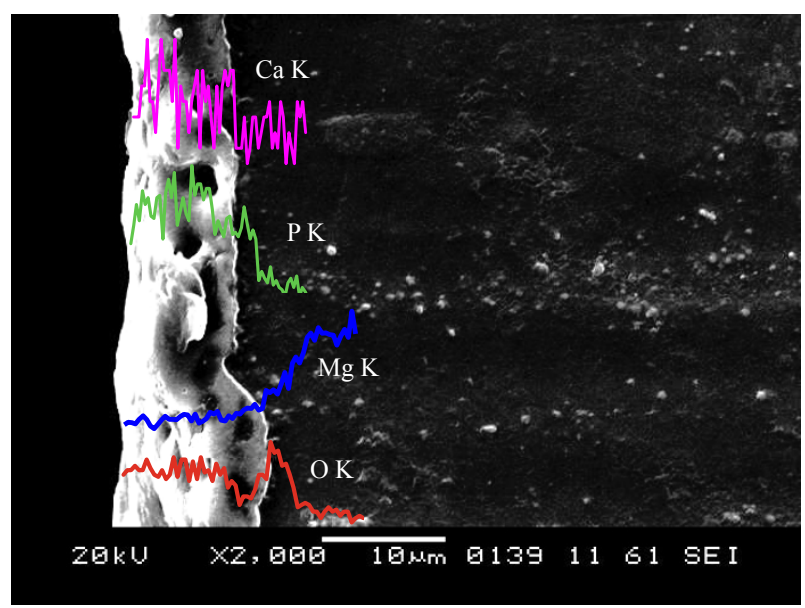

(b) $60 \mathrm{~W}$

Fig. 5 EDX of coatings line scanning analysis. 
detected by XRD.

\section{3 Corrosion resistance}

The polarization curves of different coatings under the electrochemical corrosion are examined compared to that of the substrate as shown in Fig. 6. All data are listed in Table 2. After the polarization tests, corrosion craters could be observed evidently on the surface of magnesium alloy substrate by low-magnification microscopy observation. Smooth MAO sample disappears, but there are no obvious changes. The flat UMAO coatings are still being though there is local corrosion pit (shown in Fig. 7). The $E_{\text {corr }}$ and $i_{\text {corr }}$ of the bare magnesium alloy was $-1.583 \mathrm{~V}$ and $2.529 \times$ $10^{-5} \mathrm{~A} / \mathrm{cm}^{2}$, respectively. In comparison, the $E_{\text {corr }}$ of MAO magnesium alloy obviously increases. The corrosion resistance of magnesium alloy is greatly improved by the MAO process. Furthermore, the $E_{\text {corr }}$ of UMAO coated sample is $-0.353 \mathrm{~V}$ and the $i_{\text {corr }}$ is $1.560 \times 10^{-6} \mathrm{~A} / \mathrm{cm}^{2}$. From above results, it could be seen that the corrosion rates of the coated magnesium alloys by ultrasound are greatly reduced. It also could be concluded that UMAO coatings perform the best corrosion resistance. The anticorrosion property of the ceramic coatings is decided by microstructure and chemical composition, etc. [14]. As shown in Fig. 1, the microstructure of coatings is porous, so the corrosive medium could easily enter into the porous

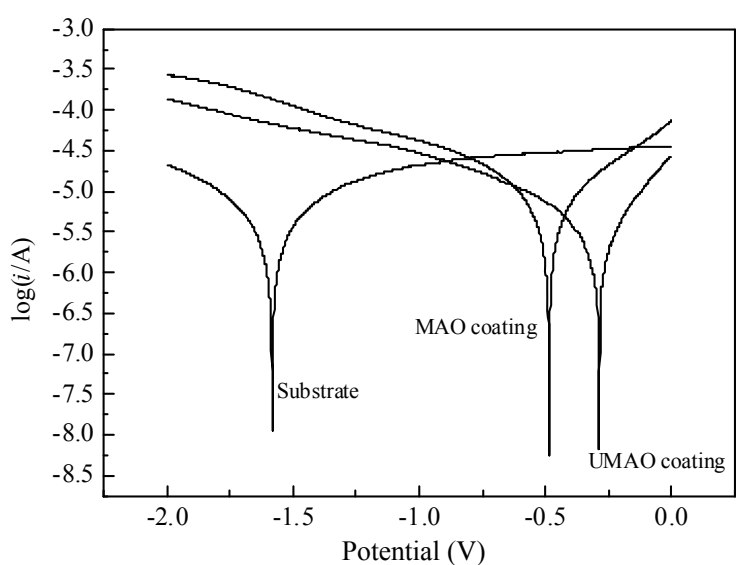

Fig. 6 Potentiodynamic polarization curves of the bare and coated magnesium alloy.

Table 2 Results of potentiodynamic corrosion tests in SBF

\begin{tabular}{ccll}
\hline Film & $E_{\text {corr }}(\mathrm{V})$ & $i_{\text {corr }}\left(\mathrm{A} / \mathrm{cm}^{2}\right)$ & $R_{\mathrm{p}}(\mathrm{k} \Omega)$ \\
\hline Bare magnesium & -1.583 & $2.529 \times 10^{-5}$ & 1.020 \\
MAO magnesium & -1.098 & $5.188 \times 10^{-6}$ & 1.945 \\
UMAO magnesium & -0.353 & $1.560 \times 10^{-6}$ & 4.888 \\
\hline
\end{tabular}

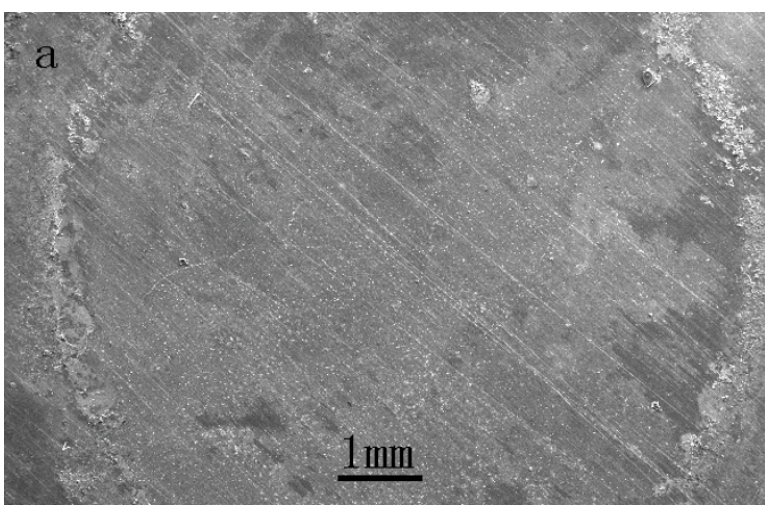

(a) substrate

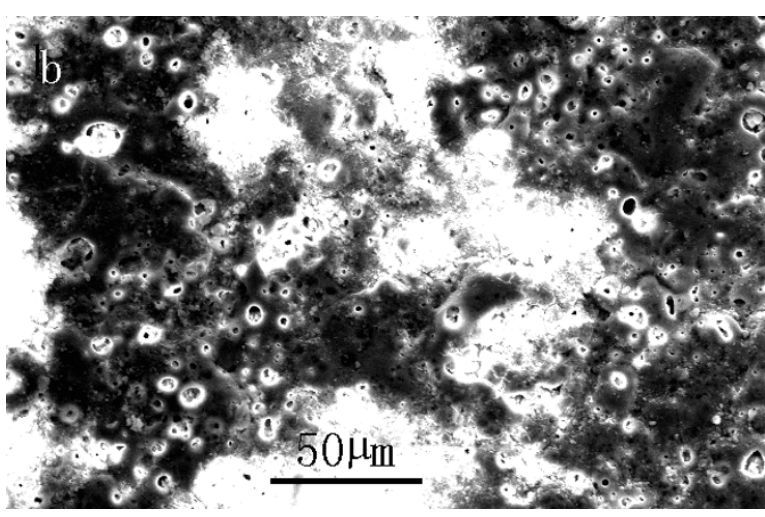

(b) MAO coating

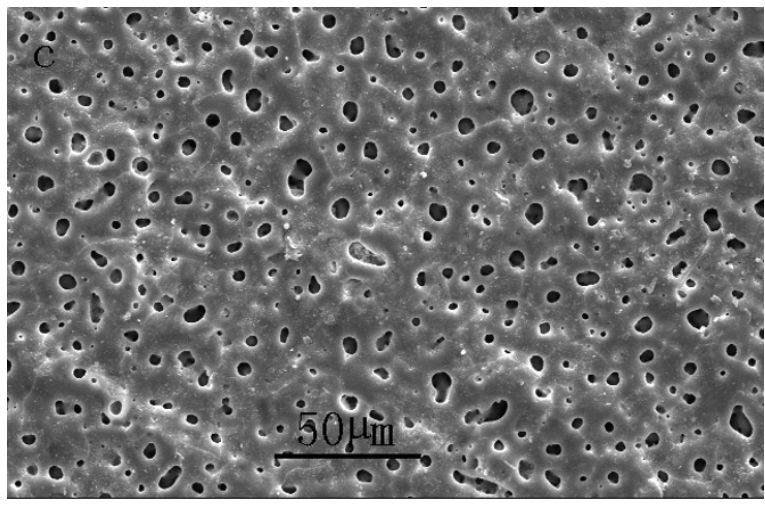

(c) UMAO coating

Fig. 7 Electrochemical corrosion morphologies of the bare and coated magnesium alloy.

film. However, ultrasound makes the movable carrier $\mathrm{O}^{2-}$ in electrolyte react with $\mathrm{Mg}^{2+}$ transferred from magnesium matrix to form the thicker dense layer, which offers more protection layer for magnesium substrate. Therefore, ultrasound in MAO could effectively improve the corrosion resistance.

\section{Conclusions}

(i) Ultrasonic improved the homogeneous distribution 
of micro-porous structure, but did not change the phase of coatings. The coatings coated with and without ultrasonic were all porous $\mathrm{MgO}$ ceramic containing small amount of calcium and phosphorus.

(ii) Ultrasonic could increase $\mathrm{Ca} / \mathrm{P}$ ratio of the ceramic coatings.

(iii) Ultrasonic could increase the corrosion resistance of magnesium alloy. Corrosion resistance of UMAO coatings was better than that of MAO coatings, and ultrasonic treatment during the process of MAO effectively decreased the corrosion rate of magnesium alloy.

\section{Acknowledgements}

The authors are grateful for the supports from the National Natural Science Foundation of China (No. 31070859) and the Natural Science Foundation of Heilongjiang Province (No. ZD201008).

Open Access: This article is distributed under the terms of the Creative Commons Attribution Noncommercial License which permits any noncommercial use, distribution, and reproduction in any medium, provided the original author(s) and source are credited.

\section{References}

[1] Witte F. The history of biodegradable magnesium implants: A review. Acta Biomater 2010, 6: 1680-1692.

[2] Hermawan H, Dubé D, Mantovani D. Developments in metallic biodegradable stents. Acta Biomater 2010, 6: $1693-1697$.

[3] Alvarez-Lopez M, Pereda MD, del Valle JA, et al. Corrosion behaviour of AZ31 magnesium alloy with different grain sizes in simulated biological fluids. Acta Biomater 2010, 6: 1763-1771.

[4] Li JN, Cao P, Zhang XN, et al. In vitro degradation and cell attachment of a PLGA coated biodegradable Mg-6Zn based alloy. J Mater Sci 2010, 45: 6038-6045.

[5] Mandelli A, Bestetti M, Da Forno A, et al. A composite coating for corrosion protection of AM60B magnesium alloy. Surf Coat Technol 2011, 205: 4459-4465.

[6] Chen H, Lv GH, Zhang GL, et al. Corrosion performance of plasma electrolytic oxidized AZ31 magnesium alloy in silicate solutions with different additives. Surf Coat Technol 2010, 205: S32-S35.

[7] Cai J, Cao F, Chang L, et al. The preparation and corrosion behaviors of MAO coating on AZ91D with rare earth conversion precursor film. Appl Surf Sci 2011, 257: 3804-3811.

[8] Yang Y, Wu H. Effects of current frequency on the microstructure and wear resistance of ceramic coatings embedded with $\mathrm{SiC}$ nano-particles produced by micro-arc oxidation on AZ91D magnesium alloy. J Mater Sci Technol 2010, 26: 865-871.

[9] Guo HF, An MZ. Growth of ceramic coatings on AZ91D magnesium alloys by micro-arc oxidation in aluminate-fluoride solutions and evaluation of corrosion resistance. Appl Surf Sci 2005, 246: 229-238.

[10] Gu XN, Li N, Zhou WR, et al. Corrosion resistance and surface biocompatibility of a microarc oxidation coating on a Mg-Ca alloy. Acta Biomater 2011, 7: 1880-1889.

[11] Liang J, Hu L, Hao J. Characterization of microarc oxidation coatings formed on AM60B magnesium alloy in silicate and phosphate electrolytes. Appl Surf Sci 2007, 253: 4490-4496.

[12] Shi L, Xu Y, Li K, et al. Effect of additives on structure and corrosion resistance of ceramic coatings on $\mathrm{Mg}-\mathrm{Li}$ alloy by micro-arc oxidation. Curr Appl Phys 2010, 10: 719-723.

[13] Lin $\mathrm{P}$, Zhou H, Li W, et al. Interactive effect of cerium and aluminum on the ignition point and the oxidation resistance of magnesium alloy. Corros $S c i$ 2008, 50: 2669-2675.

[14] Liang J, Guo B, Tian J, et al. Effects of $\mathrm{NaAlO}_{2}$ on structure and corrosion resistance of microarc oxidation coatings formed on AM60B magnesium alloy in phosphate-KOH electrolyte. Surf Coat Technol 2005, 199: 121-126.

[15] Chen J, Zeng R, Huang W, et al. Characterization and wear resistance of micro-arc oxidation coating on magnesium alloy AZ91 in simulated body fluids. Trans Nonferrous Met Soc China 2008, 18: s361-s364.

[16] Zhong L, Cao F. Shi Y, et al. Preparation and corrosion resistance of cerium-based chemical conversion coating on AZ91 magnesium alloy. Acta Metall Sin 2008, 44: 979-985 (in Chinese).

[17] Wu CS, Zhang Z, Cao FH, et al. Study on the anodizing of AZ31 magnesium alloys in alkaline borate solutions. Appl Surf Sci 2007, 253: 3893-3898.

[18] Chang L, Cao F, Cai J, et al. Formation and transformation of $\mathrm{Mg}(\mathrm{OH})_{2}$ in anodic coating using FTIR mapping. Electrochem Commun 2009, 11: 
2245-2248.

[19] Khaselev O, Yahalom J. The anodic behavior of binary $\mathrm{Mg}-\mathrm{Al}$ alloys in $\mathrm{KOH}-$ aluminate solutions. Corros Sci 1998, 40: 1149-1160.

[20] Srinivasan PB, Liang J, Blawert C. Characterization of calcium containing plasma electrolytic oxidation coatings on AM50 magnesium alloy. Appl Surf Sci 2010, 256: 4017-4022.

[21] Xu L, Pan F, Yu G, et al. In vitro and in vivo evaluation of the surface bioactivity of a calcium phosphate coated magnesium alloy. Biomaterials 2009, 30: 1512-1523.

[22] Liu GY, Hu J, Ding ZK, et al. Bioactive calcium phosphate coating formed on micro-arc oxidized magnesium by chemical deposition. Appl Surf Sci 2011, 257: 2051-2057.

[23] Yang S, Qi M, Chen Y, et al. MAO-DCPD composite coating on $\mathrm{Mg}$ alloy for degradable implant applications. Mater Lett 2011, 65: 2201-2204.

[24] Zhang Y, Lin SY, Fang Y. New developments in sonochemistry-Preparation of nanomaterials by ultrasound. Physics 2002, 31: 80-83 (in Chinese).

[25] Mo RY, Lin SY, Wang CH. Methods of study on sound cavitation. Appl Acoust 2009, 28: 389-400 (in Chinese).
[26] Cravotto G, Tagliapietra S, Robaldo B, et al. Chemical modification of chitosan under high-intensity ultrasound. Ultrason Sonochem 2005, 12: 95-98.

[27] Aurousseau M, Pham NT, Ozil P. Effects of ultrasound on the electrochemical cementation of cadmium by zinc powder. Ultrason Sonochem 2004, 11: $23-26$.

[28] Morison SR. Wu HH, translator. Electrochemistry of Semiconductor and Metal Oxide Film. Beijing: Science Press, 1988: 95-96 (in Chinese).

[29] Wu HH. Electrochemistry. Beijing: Chemical Industry Press, 2004: 218 (in Chinese).

[30] Pandey AK, Kalsi PC, Iyer RH. Effects of high intensity ultrasound in chemical etching of particleyer tracks in solid state nuclear track detectors. Nucl Instrum Meth B 1998, 134: 393-399.

[31] Wang XM, Zhu LQ, Liu HC, et al. Influence of surface pretreatment on the anodizing film of $\mathrm{Mg}$ alloy and the mechanism of the ultrasound during the pretreatment. Surf Coat Technol 2008, 202: 4210-4217.

[32] Abbasi S, Bayati MR, Golestani-Fard F, et al. Micro arc oxidized $\mathrm{HAp}-\mathrm{TiO}_{2}$ nanostructured hybrid layers-part I: Effect of voltage and growth time. Appl Surf Sci 2011, 257: 5944-5949. 